\title{
Review of the New World species of Oxytorus (Hymenoptera: Ichneumonidae: Oxytorinae), with description of two new species from Brazil
}

\author{
Santiago Bordera, ${ }^{1}$ Alejandra González-Moreno
}

\begin{abstract}
The New World fauna of the genus Oxytorus Förster, 1869 (Hymenoptera: Ichneumonidae) comprises 11 species, two of them, $O$. bahiensis new species and $O$. sinopae new species, both from eastern Brazil, are described as new. New data about distribution and variation of several species are reported. Oxytorus peruvianus Alvarado, Bordera, and Rodríguez-Berrío, 2011 is reported for the first time from Brazil and Ecuador, and $O$. alfredi Gauld and Mallet, 2000 from Guatemala, Mexico, and Trinidad and Tobago. An illustrated key to the New World species of Oxytorus is provided.
\end{abstract}

\begin{abstract}
Résumé-La faune du Nouveau Monde du genre Oxytorus Förster, 1869 (Hymenoptera: Ichneumonidae) comprend 11 espèces, dont deux du Brésil oriental: $O$. bahiensis nouvelle espèce et $O$. sinopae nouvelle espèce sont décrites comme nouvelles pour la science. De nouvelles données sur la répartition et la variabilité de plusieurs espèces sont présentées. Oxytorus peruvianus Alvarado, Bordera, et Rodríguez-Berrío, 2011 est citée pour la première fois au Brésil et en Équateur et $O$. alfredi Gauld et Mallet, 2000 au Guatemala, Mexique et Trinité-et-Tobago. Finalement, une clé pour la détermination des espèces du genre Oxytorus du Nouveau Monde est présentée.
\end{abstract}

\section{Introduction}

The Oxytorinae is a monotypic small-sized subfamily of Ichneumonidae (Hymenoptera) (Wahl 1990; Gauld 2000), comprising 19 described species belonging to the genus Oxytorus Förster, 1869 (Alvarado et al. 2011; Yu et al. 2012). From these species, nine are Palaearctic, three Nearctic, and six have Neotropical distributions ( $\mathrm{Yu}$ et al. 2012). Oytorus woolleyi (Kasparyan and RuizCancino, 2000) considered by Yu et al. (2012) as Neotropical, well could be considered Nearctic because it is only known from northern Mexico. The rest of the Neotropical species include four in Costa Rica (Gauld 2000), one of them also distributed in Mexico, and another one from South America, reported from a Peruvian premontane rain-forest (Alvarado et al. 2011). Nothing is known about the hosts of the genus, but the ovipositor form suggests they are koinobiont endoparasitoids of exposed larvae of some holometabolous insect (Gauld 2000; Kasparyan and Ruiz-Cancino 2000).

In the study of material from several important entomological collections, we found two new species from Brazil. The aim of this paper is to describe and illustrate these new species and to provide a key to all New World species of Oxytorus.

\section{Materials and methods}

We have studied material preserved in the American Entomological Institute, Gainesville, Florida, United States of America (AEIC); Natural History Museum, London, United Kingdom (BMNH); Colección Entomológica de la Universidad de Alicante, Alicante, Spain (CEUA); Canadian National Collection of Insects, Ottawa, Ontario, Canada (CNCI); Instituto Nacional de Biodiversidad, Santo Domingo de Heredia, Costa Rica (INBio); Museo de Entomología Klaus

Received 18 October 2013. Accepted 8 January 2014.

S. Bordera, ${ }^{1}$ Instituto de Investigación de Biodiversidad CIBIO (Centro Iberoamericano de Biodiversidad), Universidad de Alicante, Apdo. Corr. 99, Alicante 03080, Spain

A. González-Moreno, Instituto Tecnológico de Conkal, km 16.3 old road Merida-Motul, C.P. 97345, Conkal, Yucatán, Mexico

${ }^{1}$ Corresponding author: (e-mail: s.bordera@ua.es).

Subject editor: Bradley Sinclair

doi:10.4039/tce. 2014.33

http://zoobank.org/urn:lsid:zoobank.org:pub:AC87A48C-44E1-4358-BBAB-3871EE6DE5B4 
Fig. 1. Antenna of Oxytorus isabellae: (A) lateral view; (B) enlargement of flagellomeres 14-15 (arrows show cluster of placoid sensilla); (C) enlargement of third flagellomere (arrows show placoid sensilla).

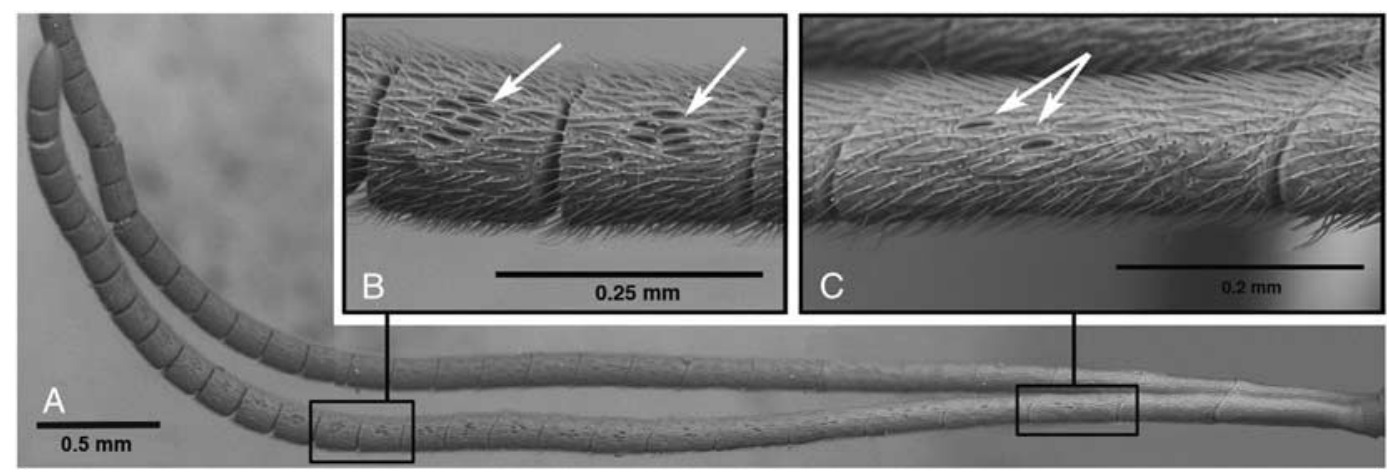

Raven Büller, Universidad Nacional Agraria la Molina, Lima, Peru (MEKRB); Insect Museum of Universidad Autónoma de Tamaulipas, Cuidad Victoria, Tamaulipas, Mexico (UAT); and Universidade Federal do Espírito Santo, Vitória, Espírito Santo, Brazil (UFES).

Observations were made using Wild (Wetzlar, Germany) M3Z stereomicroscope. Layer photographs were taken in Zoological Museum of the University of Turku (Finland) using an Olympus (Tokyo, Japan) SZX16 attached to an Olympus E520 digital camera. Digital photographs were combined using the programs Deep Focus 3.1 and QuickPHOTO CAMERA 2.3. The SEM images were taken using a Hitachi (Tokyo, Japan) S-3000N scanning electron microscope (in low vacuum mode) in the University of Alicante, Spain. Morphological terminology follows Gauld (2000). Terminology used for describing body surface sculpture is based on Eady (1968).

\section{Taxonomy}

The most distinctive features of Oxytorus are elongate maxillary palpi, at least reaching mid coxa; ovipositor sheath rigid, short, not extending beyond the tip of the metasoma and leaf-like in profile (Figs. 6E-F); subgenital plate of female large and conspicuous (Fig. 6E); and flagellomeres dorsomedially with a cluster of close small placoid sensilla (Gauld 2000). Gauld (2000) indicated that these sensilla were present on the distal flagellomeres of females. However, in our study we have seen that, at least in all Neotropical species, this cluster of small placoid sensilla is present from the second or third flagellomere to the penultimate or last one (Figs. $1 \mathrm{~A}-\mathrm{C})$. Other diagnostic characters in combination are as follows: mandible bidentate, long and slender with upper tooth longer than lower tooth (Figs. 2A-B); labrum concealed behind clypeus; clypeus broad, separated from face by a groove, basally convex, subtly flattened or weakly concave apically; occipital carina complete, joining hypostomal carina above base of mandible; malar space without groove; tyloids of male lacking; notaulus lacking or faint; sternaulus absent or weak, extending less than a third of the length of the mesopleuron (Figs. 6C-D); posterior transverse carina of the mesosternum absent; fore wing vein $2 \mathrm{~m}$-cu with one bulla; mid and hind tibia with two spurs; tarsal claws not pectinate; glymma lacking (Figs. 2C-F); sternum of first metasomal segment fused to the tergum (Figs. 2C-F); epipleura of metasomal segments 2-3 separated from tergite by a crease; metasoma compressed posteriorly. For a complete description of the genus see Gauld (2000).

\section{Key to new world species of Oxytorus}

1. Mandible elongate, stout (Fig. 2A); maximum width at base of teeth $0.5-0.7$ times the width of mandibular base; lower tooth usually reaching or exceeding half length of the upper tooth. First metasomal tergite subcylindrical in cross section at spiracle level, strongly arched in lateral view (Fig. 2C).. . . . . . 2 2 
Mandible very long and slender, quite strongly tapered towards apex (Fig. 2B); maximum width at base of teeth 0.2-0.4 times the width of mandibular base; lower tooth not reaching half length of upper tooth, often reaching only one-third of this length. First metasomal tergite flattened dorsally, slightly arched or straight

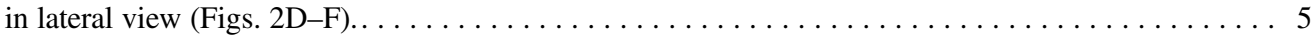

2(1). Anterior transverse carina of propodeum always absent. Lateromedian and lateral longitudinal carinae at the base of propodeum vestigial. Area superomedia strongly convergent to base of propodeum confluent with area basalis, sometimes all carinae weak or absent. Mexico.......... O. woolleyi Kasparyan and Ruiz-Cancino, 2000 Propodeum strongly and completely carinate. Area superomedia always strong and well-defined,

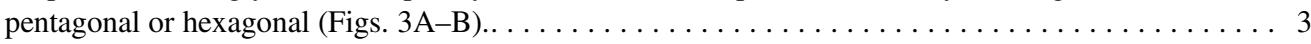

3(2). Upper end of epicnemial carina ending at anterior margin of mesopleuron. Lateral carina of scutellum only at base. Area superomedia usually as broad as long (Fig. 3A). Metasoma of female moderately short, about twice length of mesosoma, tergite II $0.6-0.8$ as long as posteriorly wide. Flagellum of female thickened in distal half. Eastern Canada and United States of America. ...... O. albopleuralis (Provancher, 1879) Upper end of epicnemial carina ending at some distance to anterior margin of mesopleuron. Lateral carina of scutellum reaching at least half length of scutellum, often ending near apex. Area superomedia clearly longer than broad (Fig. 3B). Metasoma of female, elongate usually more than 2.5 times as long as length of mesosoma, tergite II 1.1-1.7 as long as posteriorly wide. Flagellum of female filiform. . . . . . . . 4

4(3). Mesopleuron of female strongly rugose on a granulate background. Malar space of male $0.3-0.5$ times basal width of mandible. Male with strong and wide white band on the flagellum. Eastern Canada and United

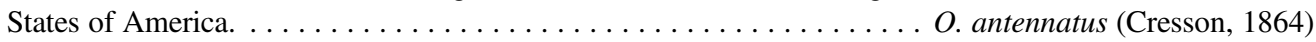
Mesopleuron of female finely punctate on a granulate background. Malar space of male $0.7-0.8$ times basal width of mandible. Male with weak or lacking white band on the flagellum. Eastern United States of

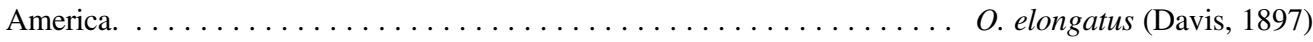

5(1). Females (with short ovipositor sheath, leaf-like in profile; Fig. $6 \mathrm{E}-\mathrm{F}) \ldots \ldots \ldots \ldots \ldots \ldots \ldots \ldots 6$

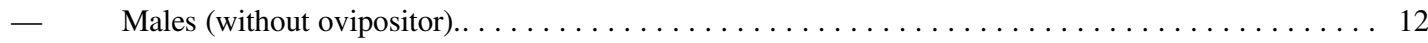

6(5). Area superomedia elongate, typically coffin shaped, more than 1.7 times as long as wide. Basal lateromedian and lateral denticles of propodeum very strong and sharp (as in Figs. 4A-B) . . . . . 7 Area superomedia different (Figs. 3C-G), sometimes absent, at most 1.6 times as long as wide. Basal lateromedian and lateral denticles of propodeum usually weak (Figs. $3 \mathrm{C}-\mathrm{G}) \ldots \ldots \ldots \ldots \ldots \ldots \ldots$

7(6). Epomia present. Tergite I always more than 2.8 times as long as posteriorly wide. Areolet mostly irregularly rhombic. Costa Rica. ............................ O. knappae Gauld and Mallet, 2000 Epomia absent. Tergite I 2.5-2.7 times as long as posteriorly wide. Areolet mostly pentagonal. Costa Rica, Mexico. .............................. isabellae Gauld and Mallet, 2000

8(6). Tergite I of metasoma, $1.7-1.8$ as long as wide posteriorly. Epomia strong and long, reaching half length of anterior margin of pronotum (Fig. 6A). Lateromedian longitudinal carinae weak anteriorly to posterior transverse carina, tending to be evanescent basally (Fig. 3C). Area superomedia short, trapezoidal, wider anteriorly than posteriorly, confluent with area basalis (Fig. 3C). Area basalis narrow, parallel sided and longer than area superomedia. Anterior transverse carina absent or at most, weakly present between lateromedian and lateral longitudinal carinae (Fig. 3C). Basal lateromedian denticles of propodeum as very weak and inconspicuous swellings (Fig. 3C). Central west and central east Brazil......... O. sinopae new species Tergite I more than twice as long as wide posteriorly. Epomia short, present as a fine ridge or absent

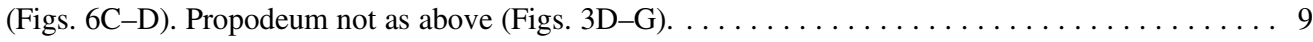

9(8). Lateromedian longitudinal carinae completely absent or faintly outlined shortly anterior to posterior transverse carina. Area superomedia and area basalis absent (Fig. 3D). Mesopleuron strongly granulate (Fig. 6C). Mesosoma and metasoma dark brown to black. Brazil, Ecuador, and Peru..................... O. peruvianus Alvarado, Bordera, and Rodríguez-Berrío, 2011 Lateromedian longitudinal carinae clearly defined anterior to posterior transverse carina. Area superomedia conspicuous, often not well defined anteriorly, confluent with area basalis or separated by several transverse wrinkles, rarely closed anteriorly by anterior transverse carina. Area basalis at most as the same length as area superomedia (Figs. 3E-G). Mesopleuron slightly granulate, tending to be smooth in part (Fig. 6D). Mesosoma and metasoma mostly or entirely reddish brown or light brown (Figs. 5D-E, 5G), rarely darker (Fig. 5F).. . . 10 
10(9). First tergite slender, more than 2.6 as long as wide. Area superomedia parallel sided posteriorly, in basal third strongly convergent to area basalis (Fig. 3E). Fore and mid coxa and trochanter white. Hind coxa light brown, with two dorsolateral wide dark brown stripes (Fig. 5E), sometimes entirely dark brown (Fig. 5F). Second and third tergite light brown; basal half of tergite II and 0.1-0.2 basal of tergite III, dark brown

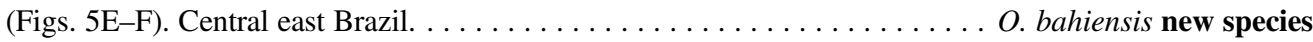
First tergite $<2.5$ times as long as wide. Area superomedia hexagonal, convergent posteriorly (Figs. 3F-G). Fore and mid coxa and trochanter, hind coxa, and second and third tergite entirely light brown to orange

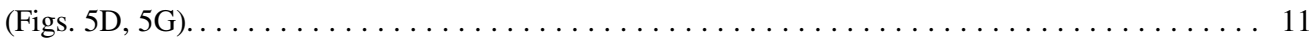

11(10). Ovipositor sheath rounded apically (Fig. 6E). First tergite short, 1.9-2.0 times as long as posteriorly wide. Malar space 0.6 times basal mandibular width. Area superomedia usually asymmetric, often defined anteriorly by a set of irregular trasverse rugae (Fig. 3F). Costa Rica, Guatemala, Mexico, and Trinidad and Tobago. ................................. alfredi Gauld and Mallet, 2000 Ovipositor sheath pointed apically (as in Fig. 6F). First tergite longer, 2.2-2.5 times as long as posteriorly wide. Malar space 0.8 times basal mandibular width. Area superomedia more or less well defined and symmetric (Fig. 3G). Costa Rica. . . . . . . . . . . . . . . . O. jamesi Gauld and Mallet, 2000

12(5). Area superomedia elongate, typically coffin shaped (Figs. 4A-B). Basal denticles of propodeum very

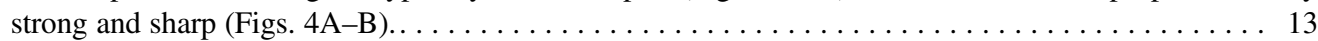
Area superomedia not coffin shaped (Figs. 4C-D), sometimes absent. Basal denticles of propodeum weak

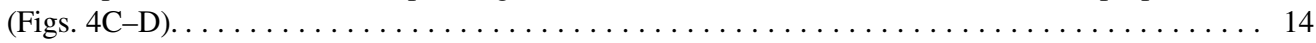

13(12). Tergite I of metasoma, quite slender, 2.8-3.3 times as long as posteriorly wide. Area superomedia about 2.0 times as long as wide (Fig. 4A). Areolet generally rhombic. Costa Rica. ..... O. knappae Gauld and Mallet, 2000 Tergite I, 2.5-2.7 as long as posteriorly wide. Area superomedia 1.5-1.7 times as long as maximum width (Fig. 4B). Areolet generally pentagonal. Costa Rica, Mexico...... O. O. isabellae Gauld and Mallet, 2000

14(12). Epomia strong, usually reaching half length of anterior margin of pronotum (Fig. 6B). Lateromedian longitudinal carinae weak anteriorly to posterior transverse carina, tending to be evanescent basally (Fig. 4C). Area superomedia short, trapezoidal, wider anteriorly than posteriorly; confluent with a narrow, long, and parallel-sided area basalis (Fig. 4C). Anterior transverse carina absent or at most shortly present at inner side of lateral longitudinal carina (Fig. 4C). Basal lateromedian denticles of propodeum as a very weak and inconspicuous swellings (Fig. 4C). Central west and central east Brazil.................. sinopae new species Epomia present as a fine ridge usually not reaching half of pronotum or absent. Propodeum not as above

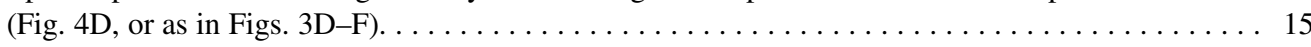

15(14). Lateromedian longitudinal carinae completely absent or faintly outlined shortly anterior to posterior transverse carina (as in Fig. 3D). Mesopleuron strongly granulate (as in Fig. 6C). Mesosoma and metasoma dark brown to black (Fig. 7C). Brazil, Ecuador, and Peru. $\ldots \ldots \ldots \ldots \ldots \ldots \ldots \ldots \ldots \ldots \ldots \ldots$. peruvianus Alvarado, Bordera, and Rodríguez-Berrío, 2011 Lateromedian longitudinal carinae clearly defined anterior to posterior transverse carina (Fig. 4D). Mesopleuron slightly granulate, tending to be smooth in large part (as in Fig. 6D). Mesosoma and metasoma mostly reddish or light brown (Fig. 7D), rarely darker.. $\ldots \ldots \ldots \ldots \ldots \ldots \ldots \ldots$

16(15). Area superomedia parallel sided posteriorly, in basal third strongly convergent to area basalis (Fig. 4D). First flagellomere entirely dark brown to black. Fore and mid coxa and trochater white. Hind coxa light brown, with two dorsolateral dark brown stripes. Second and third tergite light brown; basal half of tergite II and $0.1-0.2$ basal of

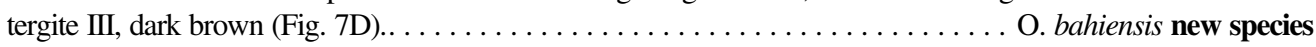
Area superomedia hexagonal, slightly asymmetric (as in Fig. 3F). First flagellomere yellow or light brown at least basally and ventrally. Fore and mid coxa and trochanter, hind coxa, and second and third tergite from entirely light brown to orange. Costa Rica, Guatemala, Mexico, and Trinidad and Tobago. .................................. alfredi Gauld and Mallet, 2000 
Fig. 2. Morphology of females: (A-B) mandible; (A) Oxytorus antennatus; (B) Oxytorus alfredi; (C-F) first tergite, lateral view: (C) Oxytorus antennatus; (D) Oxytorus sinopae (holotype); (E) Oxytorus knappae (paratype); (F) Oxytorus isabellae (paratype).
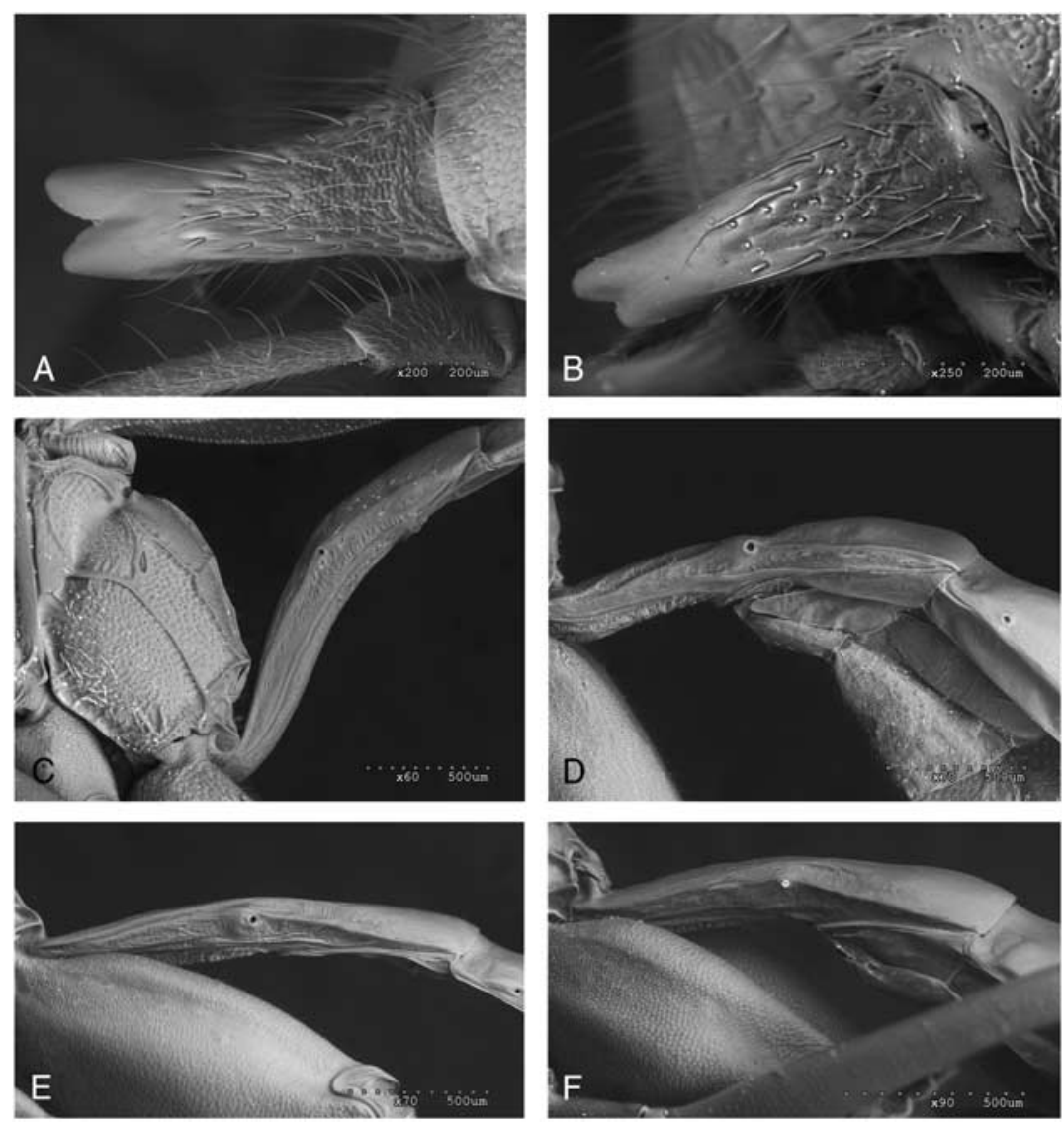

\section{Oxytorus Förster, 1869}

Oxytorus Förster, 1869: 199

Callidiotes Förster, 1869: 199 (synonym)

Delolytus Förster, 1869: 189 (synonym)

Pantoporthus Förster, 1869: 209 (synonym)

Mesatractodes Morley, 1907: 257 (synonym)

Paracanidia Viereck, 1912: 642 (synonym)

Prosmoridea Cushman, 1915: 141 (synonym)

\section{Oxytorus albopleuralis (Provancher, 1879)}

(Fig. 3A)

Mesoleptus albopleuralis Provancher, 1879: 224

Prosmosus (Prosmorus?) punctifrons Davis, 1897a: 309 (synonym)
Material examined. CANADA: 4 ऽぇ, 5 우우 from Ontario and Quebec (AEIC). UNITED

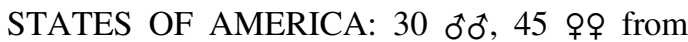
Connecticut, Kansas, Maryland, Massachusetts, Michigan, Minnesota, New Hampshire, New York, North Carolina, Ohio, Pennsylvania, South Carolina, Tennessee, and West Virginia (30 七o $^{\star}$, 44 우, AEIC, material reported by Dasch (1992); 1 \%, CEUA).

Diagnosis. Oxytorus albopleuralis can be distinguished from all New World species of Oxytorus by the following combination of characters: mandible elongate, stout (as in Fig. 2A); maximum width at base of teeth $0.5-0.7$ times the width of mandibular base; lower tooth at least reaching half length of the upper tooth. First metasomal tergite subcylindrical in cross section at spiracle 
Fig. 3. Propodeum of female, dorsal view: (A) Oxytorus albopleuralis; (B) Oxytorus antennatus; (C) Oxytorus sinopae (holotype); (D) Oxytorus peruvianus (paratype); (E) Oxytorus bahiensis (paratype); (F) Oxytorus alfredi (paratype); (G) Oxytorus jamesi (paratype).
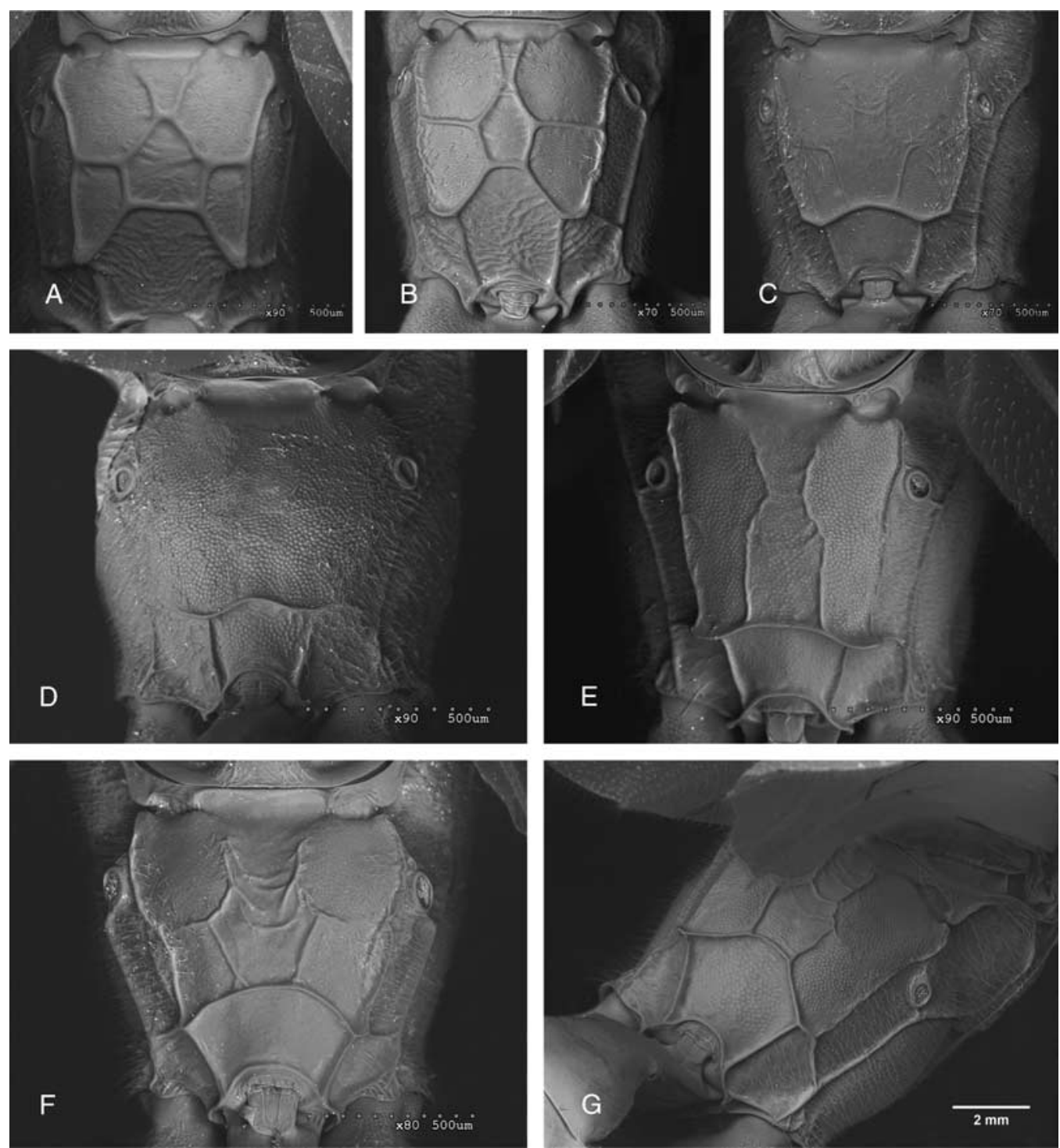

level, strongly arched in lateral view (as in Fig. 2C). Propodeum strongly and completely carinate; area superomedia pentagonal or hexagonal usually as broad as long (Fig. 3A). Upper end of epicnemial carina joining anterior margin of mesopleuron. Lateral carina of scutellum only at base. Furthermore, female has metasoma about twice length of mesosoma, tergite II $0.6-0.8$ as long as wide posteriorly and flagellum thickened in distal half.

Distribution. Eastern Canada and United States of America.

\section{Oxytorus alfredi Gauld and Mallet, 2000}

(Figs. 2B, 3F, 5D)

Oxytorus alfredi Gauld and Mallet, 2000: 427

Material examined. Paratypes reported by Gauld (2000), preserved in AEIC and BMNH. 
Fig. 4. Propodeum of male, dorsal view: (A) Oxytorus knappae (paratype), arrows show basal denticles of propodeum: a - lateromedian denticle, b - lateral denticle; (B) Oxytorus isabellae; (C) Oxytorus sinopae (paratype); (D) Oxytorus bahiensis (paratype).
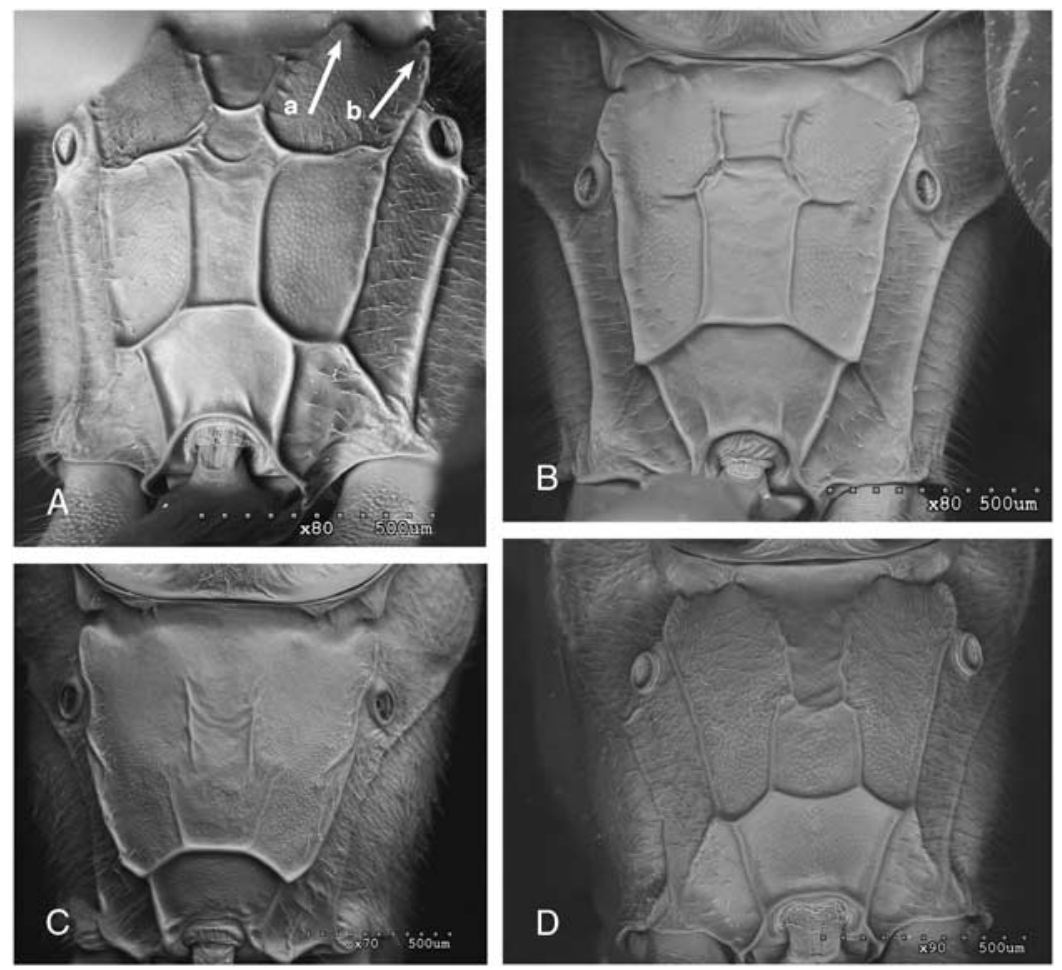

Non type material: COSTA RICA: Guanacaste Prov. Santa Rosa Park, 27.VIII.1977, 1 ơ, Dry hill, Janzen (AEIC); same locality 4.IX.1977, 1 đે, Dry hill, Janzen (AEIC); same locality, 31.X.1977,

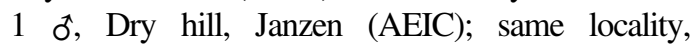
11.XI.1977, 1 ơ, Dry hill, Janzen (AEIC); same locality, 16.XI.1977, 1 ð, Dry hill, Janzen (AEIC). GUATEMALA: Guatemala Dept., Fraijanes, Finca San Antonio, $1800 \mathrm{~m}$, VI.1987, 1 đ Mauger (CEUA). MEXICO: Veracruz, $33 \mathrm{~km}$ NE Catemaco,

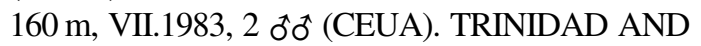
TOBAGO: Saint George, St. Agustine, 15.VII-13. VIII.1976, 1 ㅇ, J. Noyes, Malaise Trap, BM 1976462 (BMNH).

Diagnosis. Oxytorus alfredi can be distinguished from all New World species of Oxytorus by the following combination of characters: mandible very long and slender, quite strongly tapered towards apex (Fig. 2B); maximum width at base of teeth $0.2-0.4$ times the width of mandibular base; lower tooth not reaching half length of upper tooth, often reaching only

one third of this length (Fig. 2B). First metasomal tergite flattened dorsally, slightly arched or straight in lateral view (as in Figs. 2D-F), 1.9-2.0 times as long as wide posteriorly. Basal lateromedian and lateral denticles of propodeum weak (Fig. 3F). Area superomedia conspicuous, about 1.2 times as long as wide, hexagonal, usually asymmetric, convergent posteriorly, often not well defined anteriorly, confluent with area basalis or separated by several transverse wrinkles, rarely closed anteriorly by anterior transverse carina (Fig. 3F). Area basalis at most the same length as area superomedia (Fig. 3F). Epomia absent, sometimes present as a short fine ridge. Mesopleuron slightly granulate, tending to be smooth in central part (as in Fig. 6D). Ovipositor sheath rounded apically (Fig. 6E). Malar space 0.6 times basal mandibular width. Mesosoma and metasoma mostly or entirely reddish brown or light brown (Fig. 5D). Fore and mid coxae and trochanters, and hind coxa entirely light brown to orange (Fig. 5D). Male with first flagellomere yellow or light brown at least basally and ventrally. 
Fig. 5. Female habitus, lateral view: (A) Oxytorus knappae (paratype); (B) Oxytorus isabellae (paratype); (C) Oxytorus sinopae (holotype); (D) Oxytorus alfredi (paratype); (E) Oxytorus bahiensis (holotype); (F) Oxytorus bahiensis (Espírito Santo, UFES, H. C. Onody); (G) Oxytorus jamesi (holotype).
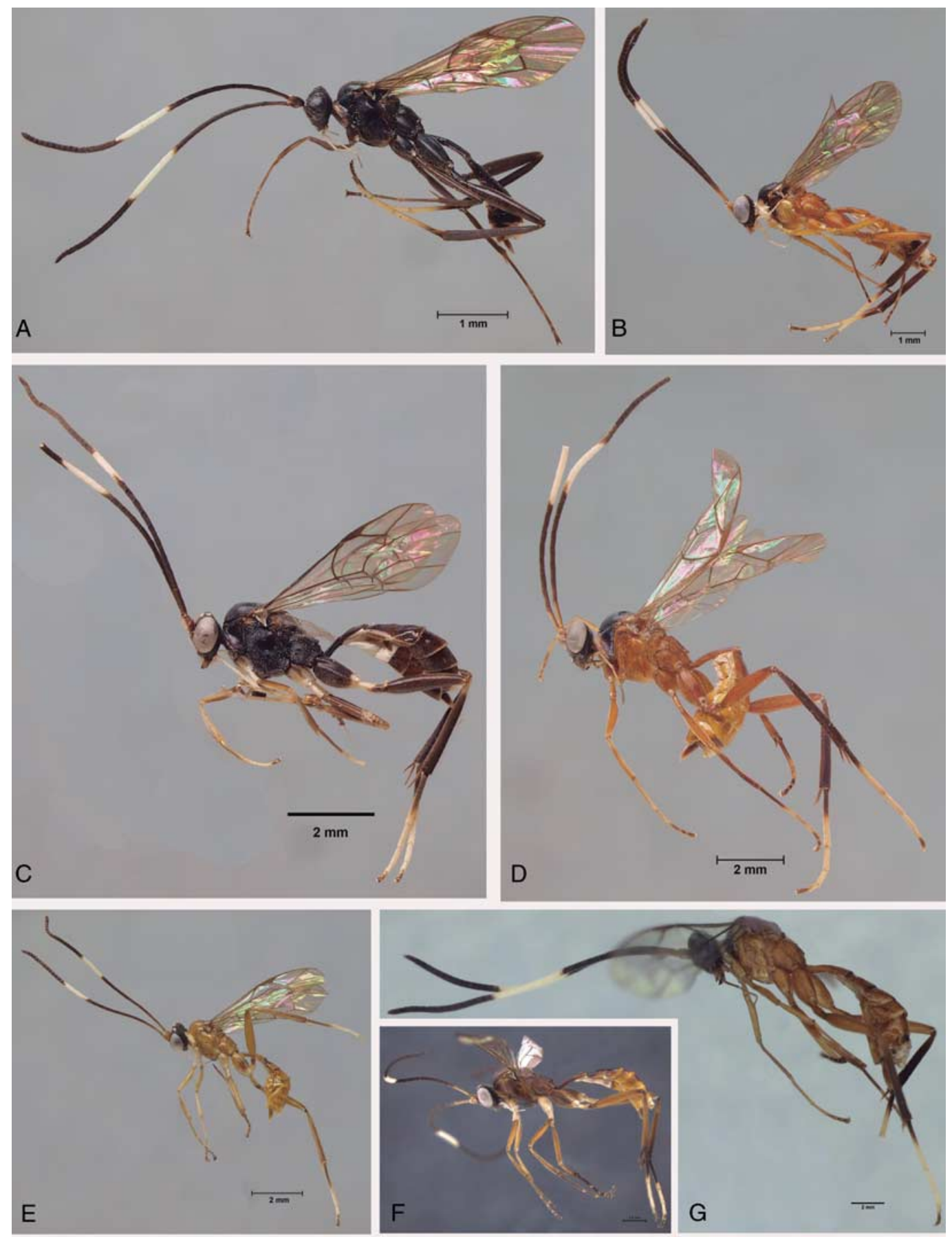
Distribution. Costa Rica. First record from Guatemala, Mexico, and Trinidad and Tobago.

\section{Oxytorus antennatus (Cresson, 1864)}

(Figs. 2A, 2C, 3B)

Mesoleptus antennatus Cresson, 1864: 272

Mesoleptus facetus Cresson, 1868: 100 (synonym) Atractodes nitens Provancher, 1882: 368 (synonym) Mesoleptus rufomixtus Provancher, 1886: 97 (synonym)

Mesoleptus filiformis Provancher, 1886: 98 (synonym)

Exolytus concamerus Davis, 1897b: 356 (synonym) Cryptus genelinii Dalla Torre, 1902: 573 (synonym) Paracanidia elyi Viereck, 1912: 643 (synonym)

Material examined: UNITED STATES OF AMERICA: 35 ऽð, 30 우 from Connecticut, Illinois, Louisiana, Maryland, Massachusetts, Michigan, Minnesota, New Hampshire, New Jersey, North Carolina, Ohio, Pennsylvania, South Carolina, and Wisconsin (34 $0^{\star} \sigma^{\star}, 28$ 우, AEIC, material reported by Dasch (1992); 1 đ, 2 우, CEUA).

Diagnosis. Oxytorus antennatus can be distinguished from all New World species of Oxytorus by the following combination of characters: mandible elongate, stout (Fig. 2A); maximum width at base of teeth $0.5-0.7$ times the width of mandibular base; lower tooth at least reaching half length of the upper tooth. First metasomal tergite subcylindrical in cross section at spiracle level, strongly arched in lateral view (Fig. 2C). Propodeum strongly and completely carinate; area superomedia pentagonal or hexagonal, clearly longer than broad (Fig. 3B). Upper end of epicnemial carina ending some distance to anterior margin of mesopleuron. Lateral carina of scutellum reaching at least half length of scutellum, often ending near apex. Furthermore, female has metasoma elongate usually more than 2.5 times as long as length of mesosoma, tergite II 1.1-1.7 as long as width posteriorly, flagellum filiform, and mesopleuron strongly rugose on granulate background. Male has malar space $0.3-0.5$ times the basal width of mandible and conspicuous wide white band on the flagellum.

Distribution: Eastern Canada and United States of America.

\section{Oxytorus bahiensis Bordera and González-Moreno, new species}

(Figs. 3E, 4D, 5E-F, 6D, 6F, 7D)

Material examined. Holotype: BRAZIL, , Bahía, Encruzilhada, 980 m, XI.1974, M. Alvarenga (AEIC). Paratypes: BRAZIL: Bahía, Encruzilhada, 980 m, XI.1974, 8 ơ ${ }^{\star}$, M. Alvarenga (AEIC); Minas Gerais, Aguas Vermelhas, $15^{\circ} 45^{\prime} \mathrm{S}$ $11^{\circ} 28^{\prime} \mathrm{W}, 800 \mathrm{~m}, \mathrm{XII} .1983,1$ o, 1 ơ, M. Alvarenga (AEIC); Minas Gerais, Piedra Azul, XI.1970, 2 ơ ơ, F.M. Oliveira, (AEIC); same locality, $800 \mathrm{~m}$, XI.1972, 1 \&, 1 đo, Alvarenga and Seabra (AEIC); Pernambuco, Caruaru, $900 \mathrm{~m}, \mathrm{~V} .1972,3$ ธิð, J. Lima (AEIC). Non-type material: BRAZIL: Espírito Santo, Santa Maria de Jetibá, Faz. Clarindo Kruger, $20^{\circ} 04^{\prime 27.9} \mathrm{\prime S} \quad 40^{\circ} 44^{\prime} 51.3^{\prime \prime W}, \quad 29 . X I-6$. XII.2002, 2 우, 4 §ðð, Malaise traps B7 and T7, M. Tavares, C. Azevedo, and eq. col. (UFES); same locality, Faz. Paulo Seike, 20 02'31.1"S $40^{\circ}$ 41'51,3"W, 6-12.XII.2002, 1 \&, Malaise Trap B1, M. Tavares, C. Azevedo, and eq. col. (UFES); same locality, Faz. Clarindo Kruger, 6-12.XII.2002, 2 ¿ $^{\star}$, Malaise trap, área 2, T5, M. Tavares, C. Azevedo, and eq. col. (UFES).

Etymology: Named after the collecting locality of the holotype in the Brazilian state of Bahía.

Diagnosis. Oxytorus bahiensis can be distinguished from all New World species of Oxytorus by the following combination of characters: mandible very long and slender, quite strongly tapered towards apex, maximum width at base of teeth 0.3-0.4 times the width of mandibular base, lower tooth reaching $0.3-0.4$ the length of upper tooth. First metasomal tergite flattened dorsally, slightly arched or straight in lateral view. Epomia absent (Fig. 6D) or, if present, as a very fine, weak ridge or sometimes replaced by several wrinkles. Mesopleuron slightly granulate, tending to be smooth in central posterior part (Fig. 6D). Basal lateromedian and lateral denticles of propodeum weak (Figs. 3E, 4D). Lateromedian longitudinal carinae clearly defined anteriorly to posterior transverse carina but usually weak. Area superomedia $<1.6$ times as long as wide, parallel sided, in basal third strongly convergent with area basalis (Figs. 3E, 4D). Mesosoma and metasoma mostly or entirely reddish brown or light brown (Figs. 5E, 7D), rarely darker (Fig. 5F). Fore and mid coxae and trochanters white. Hind coxa light brown, with two dorsolateral dark brown stripes. Second and third tergite light 
Fig. 6. Mesosoma and ovipositor of Oxytorus species, lateral view: (A-B) pronotum of Oxytorus sinopae: (A) female (holotype); (B) male (paratype); (C-D) mesopleuron of female: (C) Oxytorus peruvianus; (D) Oxytorus bahiensis; (E-F) ovipositor sheath: (E) Oxytorus alfredi; (F) Oxytorus bahiensis (paratype).
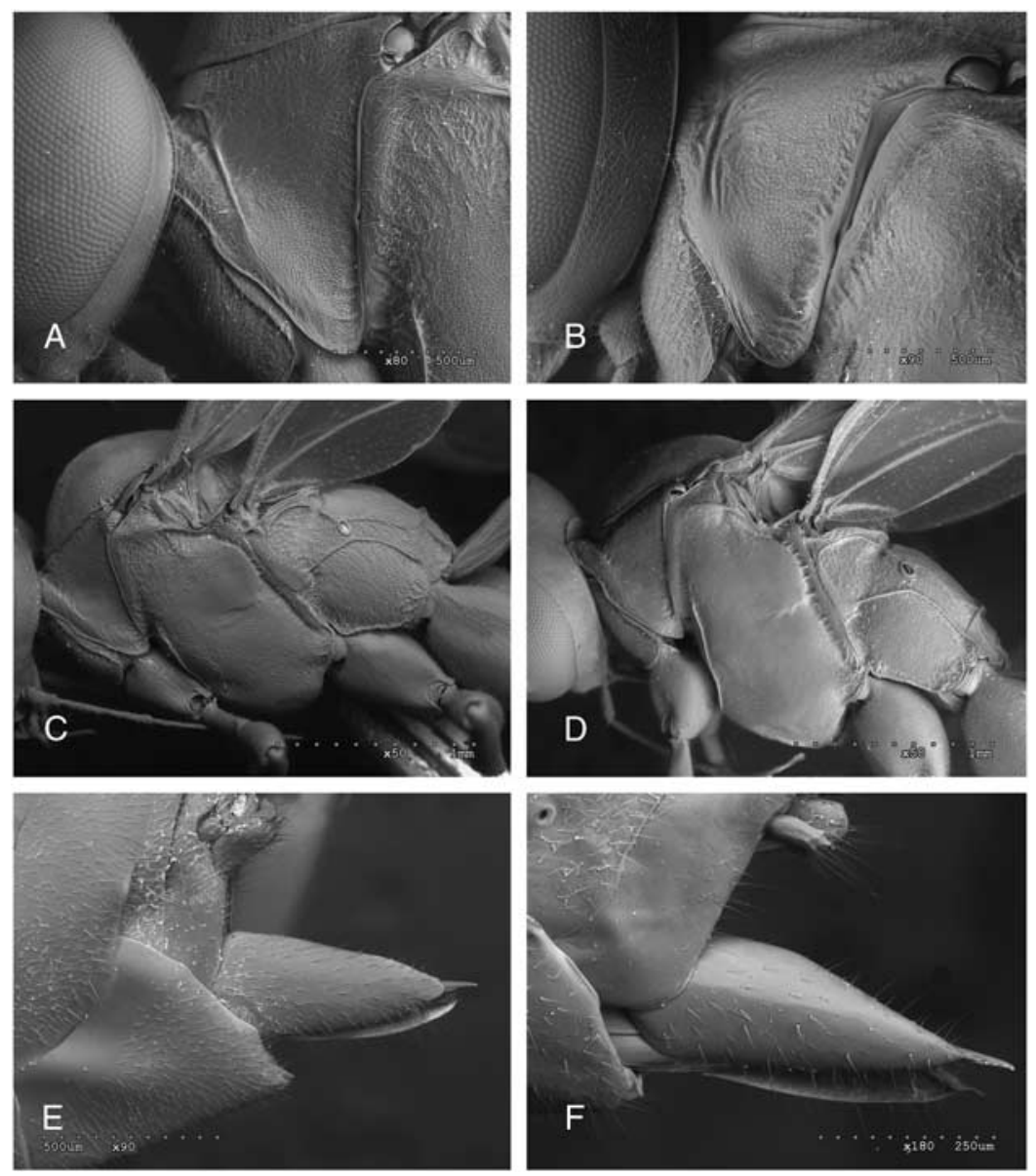

brown; basal half of tergite II and basal $0.1-0.2$ of tergite III dark brown. Additionally, female first tergite 2.6-2.8 times as long as wide posteriorly and male first flagellomere is entirely dark brown to black (Fig. 7D).

Description. Female. Body length (without ovipositor) $6.4-7.0 \mathrm{~mm}$, fore wing length $4.5-6.0 \mathrm{~mm}$.

Head. Granulate, transverse, in dorsal view, 0.5 times as long as broad. Gena 0.2-0.4 times length of eye. Antenna with 30-31 flagellomeres; third to apical flagellomeres with dorsolateral cluster of small placoid sensillae. Mandibles very long and slender, strongly tapered towards apex, maximum width at base of teeth $0.3-0.4$ times width of mandibular base, basal part granulate, apical part smooth, ventrally with sharp rim; lower tooth reaching 0.3-0.4 length of upper tooth. Malar space $0.7-0.8$ times mandibular basal width. Clypeus about 0.5 times as high as broad, abruptly convex basally, flat or weakly concave on apical 0.7 , area usually smooth and shiny, apical margin sharp and slightly rounded with long preapical setae. Posterior ocellus separated from eye by 1.0-1.1 times its maximum diameter; distance between posterior ocelli 1.0-1.4 times its maximum diameter.

Mesosoma. Mostly slightly granulate. Epomia absent (Fig. 6D) or, if present, weak as very fine ridge parallel to anterior margin, not reaching half length of anterior margin of pronotum. Notauli absent. Mesoscutum strongly granulate, slightly 
Fig. 7. Male habitus, lateral view: (A) Oxytorus woolleyi; (B) Oxytorus sinopae (paratype); (C) Oxytorus peruvianus, melanistic male; (D) Oxytorus bahiensis (paratype).
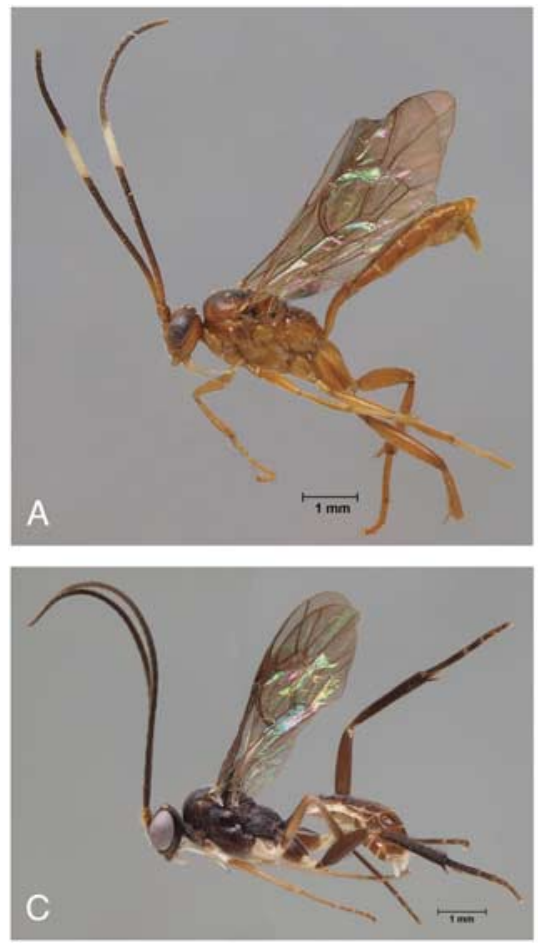
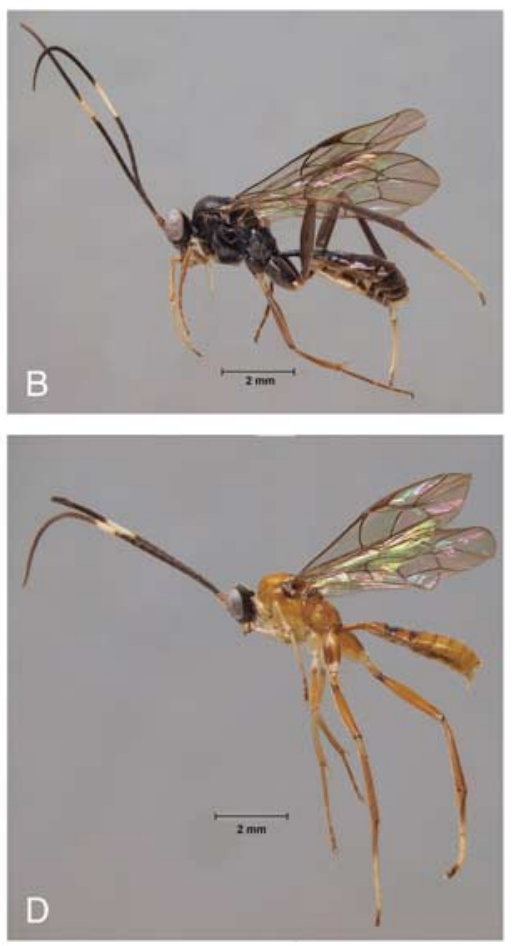

transverse carina strongly elevated and complete, forming triangular crest at point of union with lateral longitudinal carinae (Fig. 3E). Lateromedian longitudinal carinae weak but clearly defined anterior to posterior transverse carina tending to be evanescent basally; lateral longitudinal and pleural carinae from weak to moderately strong, usually complete. Area superomedia $<1.6$ times as long as wide, parallel sided, in basal third strongly convergent and confluent with area basalis (Fig. 3E). Area basalis usually shorter than area superomedia (Fig. 3E). Fore wing with areolet petiolate, triangular or pentagonal; $2 m-c u$, vertical, straight; abscissa of $M$ between $2 m-c u$ and $2 r s-m$ 0.1-0.3 times as long as abscissa between $2 m-c u$ and $3 r s-m$; first abscissa of $C u 1 a 1.3-1.6$ times as long as $C u 1 b$. Hind wing with first abscissa of $R s 1.6$ times as long as $1 r s-m$; distal abscissa of $C u 1$ present, си- $a$ 0.2-0.3 times as long as abscissa between $M$ and $C u 1.5-6$ distal hamuli.

Metasoma. Tergite I granulate tending to be smooth at posterior lateral part, slender, flattened 
dorsally, slightly arched or straight in lateral view, 2.6-2.8 times as long as wide posteriorly; lateromedian longitudinal carinae absent, lateral longitudinal and ventral lateral carinae complete. Tergite II $0.8-1.0$ as long as posteriorly broad, slightly granulate in basal half, smooth in posterior half; following tergites smooth. Thyridium transverse, oval, about 3.0 times as wide as long, conspicuously granulate. Ovipositor sheath with apex strongly pointed, $0.2-0.3$ times as long as hind tibia (Fig. 6F).

Colouration. Head mostly black; clypeus, mandible, most part of mesosoma, legs and metasoma light brown (Fig. 5E). Flagellum gradually from second flagellomere, central lobe of mesoscutum, basal half of second tergite and basal margin of third, dorsolateral stripes at hind coxa, hind trochantellus, hind first tarsomere and two distal tarsomeres brown. Anterior and median tarsi, femur distally and hind tibia dorsally fuscous. Palpi, scape, pedicel, first flagellomeres, front and mid coxae, all trochanters, distal part of tarsomere 1 and tarsomeres 2-4 of hind leg, yellow. Flagellomeres 10-14 white.

Male (Fig. 7D). Similar to female except as follows: antenna with 33-35 flagellomeres. Malar space 0.5-0.6 times basal mandibular width. Distance between posterior ocelli about 1.3 times maximum diameter. Speculum mostly smooth and shiny. Fore wing with areolet irregularly rhombic, sometimes petiolate; first abscissa of $C u 1 a 1.8$ times as long as $C u 1 b$. Hind wing with distal abscissa of $C u 1$ present, cu- $a$ 0.4-0.5 times as long as abscissa between $M$ and $C u 1$. Tergite I $2.1-2.4$ as long as posteriorly broad. Tergite I only with ventral lateral carinae present. First flagellomere dark brown; fuscous areas of median lobe and tergites of metasoma more marked; claspers, yellow cream. Flagellomeres 10-13 white.

Distribution. Central east Brazil.

Remarks. Area superomedia is variable, from weak and confluent with area basalis to strong and closed anteriorly, sometimes subsquare (Fig. 4D) or hexagonal, but always parallel sided posteriorly. Some specimens from Espírito Santo (UFES) have the same colouration pattern as the rest but they have much darker mesosoma, hind coxa and metasoma (Fig. 5F).

\section{Oxytorus elongatus (Davis, 1897)}

\section{Prosmosus (Prosmorus?) elongatus Davis,} 1897a: 310

Material examined. UNITED STATES OF AMERICA: 5 ิㅜㅎ, 2 우우 from Florida, (AEIC; material reported by Dasch, 1992).

Diagnosis. Oxytorus elongatus can be distinguished from all New World species of Oxytorus by the following combination of characters: mandible elongate, stout (as in Fig. 2A); maximum width at base of teeth $0.5-0.7$ times the width of mandibular base; lower tooth usually reaching or exceeding half length of the upper tooth. First metasomal tergite subcylindrical in cross section at spiracle level, strongly arched in lateral view (as in Fig. 2C). Propodeum strongly and completely carinate; area superomedia pentagonal or hexagonal, longer than broad. Upper end of epicnemial carina ending at some distance to anterior margin of mesopleuron. Lateral carina of scutellum ending near apex. Furthermore, female has flagellum filiform; mesopleuron finely punctate on a granulate background; metasoma elongate, usually more than 2.5 times as long as length of mesosoma and tergite II 1.3-1.4 as long as width posteriorly. Male with malar space 0.7-0.8 times basal width of mandible and white band on the flagellum lacking or very weak.

Distribution. Eastern United States of America.

\section{Oxytorus isabellae Gauld and Mallet, 2000}

(Figs. 1A-C, 2F, 4B, 5B)

Oxytorus isabellae Gauld and Mallet, 2000: 429

Material examined. Type material reported by Gauld (2000), preserved in INBio, AEIC and $\mathrm{BMNH}$. Also the male from Tamaulipas (Mexico) described by Kasparyan and Ruiz-Cancino (2000) (UAT).

Diagnosis. Oxytorus isabellae can be distinguished from all New World species of Oxytorus by the following combination of characters: mandible very long and slender, quite strongly tapered towards apex (as in Fig. 2B); maximum width at base of teeth about 0.2-0.4 times the width of mandibular base; lower tooth not reaching half length of upper tooth. First metasomal tergite 
flattened dorsally, slightly arched in lateral view (Fig. 2F), 2.5-2.7 times as long as width posteriorly. Area superomedia elongate, typically coffin shaped, about twice as long as wide in female, 1.5-1.7 times in male (Fig. 4B). Basal lateromedian and lateral denticles of propodeum very strong and sharp (Fig. 4B). Epomia absent in female, weak and short in male. Areolet mostly pentagonal.

Distribution. Costa Rica, Mexico.

Remarks. The male described by Kasparyan and Ruiz-Cancino (2000) has a weak epomia but the species is distinguishable from $O$. knappae by the shorter area superomedia and tergite I.

\section{Oxytorus jamesi Gauld and Mallet, 2000}

(Figs. 3G, 5G)

Oxytorus jamesi Gauld and Mallet, 2000: 429

Material examined. Digital images and SEM photos of holotype and paratype preserved in BMNH (Gauld 2000).

Diagnosis. Oxytorus jamesi can be distinguished from all New World species of Oxytorus by the following combination of characters: mandible very long and slender, quite strongly tapered towards apex (as in Fig. 2B); maximum width at base of teeth $0.2-0.4$ times the width of mandibular base; lower tooth not reaching half length of upper tooth, often reaching only one third of this length (as in Fig. 2B). First metasomal tergite flattened dorsally, slightly arched or straight in lateral view (as in Fig. 2D-F), 2.2-2.5 times as long as width posteriorly. Basal lateromedian and lateral denticles of propodeum weak (Fig. 3G). Area superomedia more or less well defined and symmetric $<1.6$ times as long as wide, hexagonal, convergent posteriorly (Fig. 3G). Area basalis at most as the same length as area superomedia (Fig. 3G). Epomia absent. Mesopleuron slightly granulate, tending to be smooth in central part (as in Fig. 6D). Ovipositor sheath pointed apically (as in Fig. 6F). Malar space 0.8 times the basal mandibular width. Mesosoma and metasoma mostly or entirely reddish brown or light brown (Fig. 5G). Fore and mid coxae and trochanters, and hind coxa, entirely light brown to orange (Fig. 5G). Male unknown.

Distribution. Costa Rica

\section{Oxytorus knappae Gauld and Mallet, 2000}

(Figs. 2E, 4A, 5A)

Oxytorus knappae Gauld and Mallet, 2000: 430

Material examined. Type material reported by Gauld (2000) preserved in INBio, AEIC, and BMNH (holotype 우; 31 우, 30 ơ ô paratypes from San José province, Costa Rica).

Diagnosis. Oxytorus knappae can be distinguished from all New World species of Oxytorus by the following combination of characters: mandible very long and slender, quite strongly tapered towards apex (as in Fig. 2B); maximum width at base of teeth about 0.2-0.4 times the width of mandibular base; lower tooth not reaching half length of upper tooth. First metasomal tergite flattened dorsally, slightly arched in lateral view (Figs. 2E, 5A), always more than 2.8 times as long as posteriorly wide. Area superomedia elongate, typically coffin shaped, more than 1.7 times as long as wide (Fig. 4A). Basal lateromedian and lateral denticles of propodeum very strong and sharp (Fig. 4A). Epomia present as a short low ridge.

Distribution. Costa Rica.

\section{Oxytorus peruvianus Alvarado, Bordera, and Rodríguez-Berrío, 2011}

(Figs. 3D, 6C, 7C)

Oxytorus peruvianus Alvarado, Bordera, and Rodríguez-Berrío, 2011: 867

Material examined. Type material reported by Alvarado, Bordera, and Rodríguez-Berrío (2011), preserved in MEKRB and CEUA. Non type material: BRAZIL: Mato Grosso, Sinop, $12^{\circ} 31$ 'S 55³7'W, X.1976, 1 ơ, M. Alvarenga (AEIC); Pará, Tucuruí, I.1979, 1 đo, M. Alvarenga (AEIC); Vila Vera, W50³0'S12³0', X.1973, 1 ơ, M. Alvarenga. ECUADOR: Napo, Limoncocha,

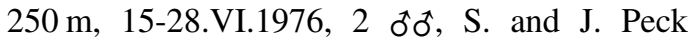
(AEIC); Napo, Tena, 10-16.II.1986, 1 ㅇ, Finnamore and Genier (AEIC); Sucumbios, Río Napo, Sacha Lodge, $0.5^{\circ} \mathrm{S}, 76.5^{\circ} \mathrm{W}, 290 \mathrm{~m}, 31 . \mathrm{X}-10$. XI.1994, 5 ỡ ơ, Hibbs (AEIC).

Diagnosis. Oxytorus peruvianus can be distinguished from all New World species of 
Oxytorus by the following combination of characters: mandible very long and slender, quite strongly tapered towards apex (as in Fig. 2B); maximum width at base of teeth about $0.2-0.4$ times the width of mandibular base; lower tooth not reaching half length of upper tooth. First metasomal tergite flattened dorsally, slightly arched or straight in lateral view (as in Fig. 2D-F), 2.0-2.3 times as long as wide posteriorly. Basal lateromedian and lateral denticles of propodeum usually weak (Fig. 3D). Epomia short, present as a fine ridge or absent (Fig. 6C). Lateromedian longitudinal carinae of propodeum completely absent or faintly outlined short anterior to posterior transverse carina (Fig. 3D). Area superomedia and area basalis absent (Fig. 3D). Mesopleuron strongly granulate (Fig. 6C). Mesosoma and metasoma dark brown to black (Fig. 7C).

Distribution: Peru. New record from Brazil and Ecuador.

Remarks. The female from Ecuador lacks the epomia, but a better revision of all paratypes of $O$. peruvianus reveals considerable variation in the development of the epomia, from conspicuous and strong, to very reduced, weak or virtually absent. Males from Brazil and Ecuador differ also from Peruvian males in the absence of the flagellar white ring and the hind tarsi being entirely brown. Certainly they could belong to a new species but no other differential characters were found, so we assigned them to this species considering that this colour variation has also been described in other species such as $O$. albopleuralis, in which dark melanistic males lack the white flagellar band (Dasch 1992). Moreover, males of O. elongatus typically lack white flagellar band, but Dasch (1992) also assigned males that lacked the white band or had only a weak band to this species.

\section{Oxytorus sinopae Bordera and González-Moreno, new species}

(Figs. 2D, 3C, 4C, 5C, 6A-B, 7B)

Material examined. Holotype: BRAZIL. ㅇ, Mato Grosso, Sinop, 12³1'S 55³7'W, X.1976. M. Alvarenga (AEIC). Paratypes: BRAZIL. Bahía, Encruzilhada, XI.1974, 980 m, 5 ธึơ, M. Alvarenga (AEIC).
Etymology. Named after the type locality of the holotype, Sinop, city in the Brazilian state of Mato Grosso.

Diagnosis. Oxytorus sinopae can be distinguished from all New World species of Oxytorus by the following combination of characters: mandible very long and slender, quite strongly tapered towards apex, maximum width at base of teeth $0.3-0.4$ times the width of mandibular base; lower tooth reaching one-third the length of upper tooth. First metasomal tergite flattened dorsally, straight in lateral view (Fig. 2D) (1.7-1.8 times as long as posterior width in female). Epomia strong, reaching half length of anterior margin of pronotum (Figs. 6A-B). Basal lateromedian denticles of propodeum very weak and inconspicuous (Figs. 3C, 4C). Lateromedian longitudinal carinae weak anteriorly to posterior transverse carina, tending to be evanescent basally (Figs. 3C, 4C). Area superomedia short, trapezoidal, wider anteriorly than posteriorly, confluent with area basalis (Figs. 3C, 4C). Area basalis weak, parallel sided, narrower and longer than area superomedia. Anterior transverse carina absent or at most, shortly and slightly traced between lateromedian and lateral longitudinal carinae (Figs. 3C, 4C).

Description. Female: Body length (without ovipositor) $6.5 \mathrm{~mm}$, fore wing length $6.0 \mathrm{~mm}$.

Head. Granulate, transverse, in dorsal view, 0.5 times as long as broad. Gena 0.2-0.3 times length of eye. Antenna with 34 flagellomeres; third to apical flagellomeres with dorsolateral cluster of small placoid sensillae. Mandibles very long and slender, strongly tapered towards apex, maximum width at base of teeth 0.3-0.4 times width of mandibular base, basal part granulate, apical part smooth, ventrally and dorsally in basal half with sharp rim; lower tooth reaching about 0.3 length of upper tooth. Malar space 0.7 times mandibular basal width. Clypeus about 0.5 times as high as broad, abruptly convex basally, flat or weakly concave on apical 0.7 , area usually smooth and shiny, with long and sparse setae, apical margin sharp and slightly rounded with long preapical setae. Posterior ocellus separated from eye by 0.9 times its maximum diameter; distance between posterior ocelli 0.9 times its maximum diameter.

Mesosoma. Mostly strongly granulate. Pronotum with a strong sharp epomia reaching about half length of anterior margin, convergent to anterior margin (Fig. 6A). Notauli absent. Mesoscutum 
strongly granulate, slightly shiny or matt. Scutellum strongly convex, without lateral carinae. Mesopleuron strongly granulate with short silvery setae; speculum strongly granulate tending to be less granulate to smooth above mesopleural impression. Epicnemial carina incomplete (not curving to meet anterior edge of mesopleuron) with dorsal end reaching about 0.2 above level of ventral corner of pronotum. Sternaulus wide and slightly impressed in anterior half of mesopleuron, obsolescent posteriorly. Posterior margin of metanotum expanded into two lateral triangular teeth, outer lateral larger than inner one, with teeth opposite of low prominences or denticles on propodeum (Fig. 3C). Metapleuron granulate about 1.3 times as long as deep, with submetapleural carina strongly broadened anteriorly. Propodeum granulate with long dense silvery pilosity at lateral parts; basal lateromedian and lateral denticles weak, lateromedian denticles as inconspicuous swellings (Fig. 3C); anterior transverse carina absent or at most, shortly and slightly traced between lateromedian and lateral longitudinal carinae (Fig. 3C); posterior transverse carina strong and complete, forming triangular crest at point of union with lateral longitudinal carina (Fig. 3C). Lateromedian longitudinal carinae weak anteriorly to posterior transverse carina, tending to be evanescent basally (Fig. 3C); lateral longitudinal and pleural carinae strong and complete. Area superomedia short, trapezoidal, wider anteriorly than posteriorly, confluent with area basalis. Area basalis parallel sided, narrower and longer than area superomedia (Fig. 3C). Fore wing with areolet irregularly rhombic; $2 m-c u$, vertical, slightly curved; abscissa of $M$ between $2 m-c u$ and 2rs- $m$ 0.4-0.5 times as long as the abscissa between $2 m-c u$ and 3rs-m; first abscissa of $C u 1 a 1.7$ times as long as $C u 1 b$. Hind wing with first abscissa of $R s 1.4$ times as long as 1 rs-m; distal abscissa of $C u 1$ present. $c u-a$ about 0.2 times as long as abscissa between $M$ and Cu1; 5-6 distal hamuli.

Metasoma. Tergite I granulate tending to be smooth at posterior part, flattened dorsally, almost straight in lateral view (Fig. 2D), strongly broadened posteriorly, 1.7-1.8 times as long as posteriorly broad; lateromedian longitudinal carinae absent, lateral longitudinal and ventral lateral carinae complete. Tergite II 0.7 as long as posteriorly broad, very slightly granulate basally smooth posteriorly, following tergites smooth. Thyridium transverse, rectangular, about 4.3 times as wide as long, slightly granulate. Ovipositor sheath pointed at apex, about 0.2 times as long as hind tibia.

Colouration. Dark brown to black (Fig. 5C). Metasoma except petiole, reddish brown. Front leg, clypeus, and mandible light brown. Mid leg brown. Hind leg dark brown. Palpi, scape below, flagellomeres 10-14 seen from above, distal half of anterior and mid coxae, apex of hind coxa, trochanters, apical half of all first tarsomere and tarsomeres 2-4, sternal parts of postpetiole, sternites II and III, posterior part of tergites VI-VIII centrally, white. Hind rim of tergites II-IV, base of median and hind tibia and apex of ovipositor sheath, yellow-cream. Wings hyaline slightly tinged of yellow.

Male (Fig. 7B). Similar to female except as follows: body length $7.0-9.0 \mathrm{~mm}$; fore wing length 11-12 mm; antenna with 37-38 flagellomeres. Posterior ocellus separated from eye by 0.7-0.9 times its own maximum diameter; distance between posterior ocelli 1.0-1.1 times its own maximum diameter. Fore wing with areolet sometimes open. Tergite I, 1.9-2.2 as long as posteriorly wide. Dorsal posterior part of tergites VII-VIII and claspers white.

Distribution. Central west and central east Brazil.

\section{Oxytorus woolleyi Kasparyan and Ruiz-Cancino, 2000}

(Fig. 7A)

Oxytorus woolleyi Kasparyan and Ruiz-Cancino, 2000: 126

Material examined. Type material reported by Kasparyan and Ruiz-Cancino (2000) preserved in UAT. Non-type material: MEXICO: Sinaloa, 15 miles W. El Palmito, 5000', 16.VII.1964, 1 ơ, W.R.M. Mason (CNCI).

Diagnosis. Oxytorus woolleyi can be distinguished from all New World species of Oxytorus by the following combination of characters: mandible elongate, stout (as in Fig. 2A); maximum width at base of teeth $0.5-0.6$ times the width of mandibular base; lower tooth reaching or exceeding half length of the upper tooth. First metasomal tergite subcylindrical in cross section at spiracle level, strongly arched in lateral view (Fig. 7A). Anterior transverse carina of propodeum absent. Lateromedian and lateral longitudinal carinae at the base of propodeum vestigial. Area superomedia 
parallel sided posteriorly, strongly convergent anteriorly and confluent with area basalis, sometimes all carinae hardly traceable or virtually absent.

Distribution. Mexico.

\section{Acknowledgements}

The authors are grateful to Dr. Ronald Zuñiga and Manuel Solís (INBio, Costa Rica), Dr. David Wahl (American Entomological Institute, Gainesville, United States of America), and Dr. Enrique RuízCancino (Insect Collection UAT, Tamulipas, Mexico), for permitting us to study type material during visits to their institutions and to Dr. Andrew Bennett for loaning the material from CNCI. Special thanks to Dr. Helena C. Onody (Federal University of São Carlos, São Paulo, Brazil) for selflessly giving us data and photographs of the non-type $O$. bahiensis specimens, as well as for allowing us the use of layer photographs in this publication. We also express our sincere gratitude to Dr. Ilari Sääksjärvi (University of Turku, Finland) for his help in taking layered digital photographs of species habitus, to Dr. Gavin Broad from BMNH for sending us material and taking digital photographs of O. jamesi, and to Dr. Marina Mazón for taking SEM photographs of $O$. jamesi in BMNH. This paper was supported partially by project A/013484/07 from Agencia Española de Cooperación Internacional para el Desarrollo (Ministerio de Asuntos Exteriores y de Cooperación, Spain).

\section{References}

Alvarado, M., Bordera, S., and Rodríguez-Berrio, A. 2011. First record of Oxytorinae (Hymenoptera: Ichneumonidae) from South America, with description of a new species of Oxytorus Förster, 1869. Biologia, 66/5: 866-869. doi:10.2478/s11756-011-0087-1.

Cresson, E.T. 1864. Descriptions of North American Hymenoptera in the collection of the Entomological Society of Philadelphia. Proceedings of the Entomological Society of Philadelphia, 3: 257-321.

Cresson, E.T. 1868. A list of the Ichneumonidae of North America, with descriptions of new species. Transactions of the American Entomological Society, 2: 89-114.

Cushman, R.A. 1915. Descriptions of new Ichneumonidae and taxonomic notes. Proceedings of the Entomological Society of Washington, 17: 132-142.

Dalla Torre, C.G. de. 1902. Catalogus Hymenopterorum. Volumen III. Trigonalidae, Megalyridae, Stephanidae, Ichneumonidae, Agriotypidae, Evaniidae, Pelecinidae. Guilelmi Engelmann, Leipzig, Germany.
Dasch, C.E. 1992. The ichneumon-flies of America north of Mexico: Part 12. Subfamilies Microleptinae, Helictinae, Cylloceriinae and Oxytorinae (Hymenoptera: Ichneumonidae). Memoirs of the American Entomological Institute, 52: 1-470.

Davis, G.C. 1897a. A review of the ichneumonid subfamily Tryphoninae. Transactions of the American Entomological Society, 24: 193-348.

Davis, G.C. 1897b. Descriptions of new species of Trigonalidae, Stephanidae and Ichneumonidae. Transactions of the American Entomological Society, 24: 349-372.

Eady, R.D. 1968. Some illustrations of microsculpture in the Hymenoptera. Proceedings of the Royal Entomological Society of London, 43: 66-72.

Förster, A. 1869. Synopsis der Familien und Gattungen der Ichneumonen. Verhandlungen des Naturhistorischen Vereins der Preussischen Rheinlande und Westfalens, 25: 135-221.

Gauld, I.D. 2000. The Ichneumonidae of Costa Rica 3. Introduction and keys to species of the subfamilies: Brachycyrtinae, Cremastinae, Labeninae, and Oxytorinae, and with an appendix on the Anomaloninae. Memoirs of the American Entomological Institute, 63: $1-453$.

Kasparyan, D.R. and Ruiz-Cancino, E. 2000. First record of the subfamily Oxytorinae (Hymenoptera: Ichneumonidae) in Mexico, and description of a new species. Anales del Instituto de Biologia Universidad Nacional Autónoma de México Serie Zoologia, 71: 125-131.

Morley, C. 1907. Ichneumonologia Britannica, II. The Ichneumons of Great Britain. Cryptinae. James H. Keys, Plymouth, United Kingdom.

Provancher, L. 1879. Faune canadienne. Les insectes Hyménoptères. Naturaliste Canadien, 11: 205-233.

Provancher, L. 1882. Faune Canadienne. Hyménoptères. Additions et corrections. Naturaliste Canadien, 13: $353-368$.

Provancher, L. 1886. Additions et corrections au Volume II de la Faune Entomologique du Canada. Traitant des Hyménoptères. C. Darveau, Ville de Québec, Québec, Canada.

Viereck, H.L. 1912. Contributions to our knowledge of bees and ichneumon-flies, including descriptions of twenty-one new genera and fifty-seven new species of ichneumon-flies. Proceedings of the United States National Museum, 42: 613-648.

Wahl, D. 1990. A review of the mature larvae of Diplazontinae, with notes on larvae of Acaenitinae and Orthocentrinae and proposal of two new subfamilies (Insecta: Hymenoptera, Ichneumonidae). Journal of Natural History, 24: 27-52.

Yu, D.S., van Achterberg, K., and Horstmann, K. 2012. Taxapad 2012. World Ichneumonoidea 2011. Taxonomy, biology, morphology and distribution. Database on USB flash-drive. www.taxapad.com, Ottawa, Ontario, Canada. 